\title{
La tecnología como territorio de la co-construcción del conocimiento en el campo del hábitat
}

Paula Peyloubet

Arquitecta. Magíster en Desarrollo Urbano. Doctora en Arquitectura. Investigadora del CONICET. Profesora de posgrado. Directora del Programa de Investigación Co-construcción del Conocimiento, con sede en Centro de Investigaciones y Estudios sobre Cultura y Sociedad. CIECS-CONICET-UNC. Directora de investigadores y tesistas doctorales. Miembro de comisiones de evaluación en el campo de la investigación. Autora de múltiples libros, artículos y capítulos de libros. Directora de Desarrollos Tecnológicos Co-construidos. Línea de investigación: circuitos productivos interactorales.

paulapeyloubet@conicet.gov.ar, paulapeyloubet@hotmail.com.

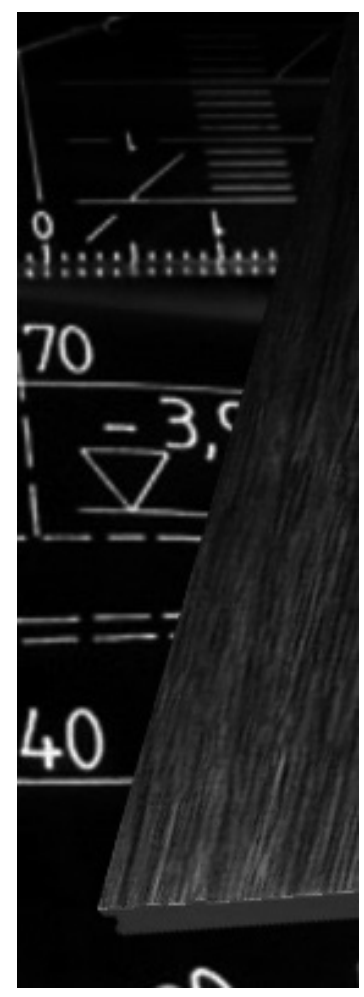

http://dx.doi.org/10.30972/crn.26263831 ISNN 1666-6186. Volumen 26 N. ${ }^{\circ} 26$ (Junio de 2019) Pp. 187-206 - Recibido: 05-04-19. Aprobado: 24-06-19 


\section{La tecnología como territorio \\ de la co-construcción \\ del conocimiento en \\ el campo del hábitat}

\section{Resumen}

El artículo presenta una introducción que instala dos ejes, la provocación epistémica y el concepto triádico de la tecnología. La primera sección, base teórica, convida autores precursores de la producción de conocimiento colectivo, que desafiando las convenciones del método científico ponen en rango epistémico el saber de sentido común. Esta parte sostiene dos dimensiones tecnológicas: la democrática y la colaborativa. La segunda sección, base empírica, comparte una experiencia tecnológica en el marco de un proceso democrático y colectivo que resultó ser una lección compartida que alimentó la teoría. La tercera sección, base metodológica, eleva la conversación al estatus de instrumento de acción, como puente cognitivo, para promover la co-construcción de conocimiento. Por último, unas conclusiones no finales reflexionan acerca de una serie de criterios que iluminan acciones tendientes hacia la co-construcción del conocimiento en un territorio atravesado por la tecnología.

\section{Palabras clave}

Tecnología; epistemología; metodología; co-construcción del conocimiento.

\section{Technology as territory of the co-construction of knowledge in the field of habitat}

\begin{abstract}
The article presents an introduction that installs two axes, the epistemic provocation and the triadic concept of technology. The first section, theoretical basis, invites precursor authors of the production of collective knowledge, who, challenging the conventions of the scientific method, put in epistemic range the knowledge of common sense. This part supports two technological dimensions: democratic and collaborative. The second section, an empirical basis, shares a technological experience within the framework of a democratic and collective process that turned out to be a shared lesson that fed the theory. The third section, methodological basis, elevates the conversation to the status of an instrument of action, as a cognitive bridge, to promote the co-construction of knowledge. Finally, some non-final conclusions reflect on a series of criteria that illuminate actions towards the co-construction of knowledge in a territory crossed by technology.
\end{abstract}

\section{Tecnologia como território \\ da co-construção \\ do conhecimento \\ no campo do habitat}

\section{Resumo}

O artigo apresenta uma introdução que instala dois eixos, a provocação epistémica e o conceito triádico da tecnologia. A primeira seção, base teórica, convida aos autores precursores da produção do conhecimento coletivo, que desafiando as convenções do método científico, põem em gama epistêmica o saber do senso comum. Esta parte sustenta duas dimensões tecnológicas: a democrática e a colaborativa. A segunda seção, base empírica, compartilha uma experiência tecnológica no âmbito de um processo democrático e coletivo que acabou sendo uma lição compartilhada que alimentou a teoria. A terceira seção, base metodológica, eleva a conversação ao status de instrumento de ação, como ponte cognitiva, para promover a co-construção do conhecimento. Finalmente, algumas conclusões não finais refletem sobre uma série de critérios que iluminam ações tendentes à co-construção do conhecimento em um território atravessado pela tecnologia.

\section{Palavras chave}

Tecnologia; epistemologia; metodologia, co-construção do conhecimento. 


\section{Introducción}

\section{La provocación epistémica de la co-construcción del conocimiento}

En la actualidad existen corrientes de pensamiento que se instalan en las márgenes del paradigma positivista generando puentes entre el conocimiento científico, occidental y hegemónico, devenido en códices, y el conocimiento de sentido común emanado de tradiciones no hegemónicas, construido desde la palabra y las vivencias.

El recorrido teórico que se presenta en este artículo acerca a algunos autores referentes, precursores de una nueva tradición epistémica, cuestionadora, provocadora y desafiante, que intenta componer, a partir de los atributos de la libertad cognitiva, una comprensión del mundo que dé lugar a una democrática selección de estilos de vida que no necesariamente se enmarcan en los modelos globales de civilización occidental. Igualmente, este artículo no pretende ser un estudio pormenorizado de cada autor y su obra, sino que procura, con la voz de cada uno de ellos, argumentar la posición que enarbola la construcción colectiva del conocimiento y la valoración superlativa de la comunidad no académica dentro de estos procesos cognoscentes, que tiene mucho por señalar, en función de la utilidad social del conocimiento, y aportar, sobre la base del conocimiento experto no científico.

La argumentación tiene, como hilo conductor de los relatos, la presencia injustamente postergada de la comunidad extracientífica cuya racionalidad no reproduce la lógica de las problematizaciones del método científico, sino que fomenta otras racionalidades, asentadas sobre procesos conscientes o inconscientes, que operan en la vida cotidiana reproduciendo un sentido común atribuible a tradiciones cognitivas basadas en la experiencia práctica y los aprendizajes no formales ni institucionalizados. Siendo este el reclamo, el artículo procurará tomar su pensamiento para traducirlo en un mensaje renovado que aluda a la cuestión tratada en La tecnología como territorio de la co-construcción del conocimiento. 
La elección de los autores es producto de una exhaustiva selección que pretende dar cuenta del posicionamiento epistémico del presente trabajo. La traducción interpretativa será asimilable a una visión transformadora de los abordajes epistémicos en el campo del Hábitat a partir de la producción tecnológica, y no necesariamente constituirá la expresión exacta de cada referente, sino más bien la interpretación creativa y libre de la autora de este artículo.

\section{La tecnología y su tríada argumental}

El concepto de tecnología, que se presenta aquí, articula tres argumentos distinguibles a nivel analítico (es decir, son elementos distinguibles desde un punto de vista académico, pero no presentan diferencias sustanciales en el acontecer práctico): tecnología producto, tecnología proceso y tecnología gestión (DaGnino, 2010). El primer sentido que emerge de esa distinción analítica son los diferentes anclajes en la realidad que cada uno implica, donde el producto supone lo artefactual, el proceso refiere a la trama de relaciones interactorales en las que se produce conocimiento y la gestión aborda las interrelaciones que se generan entre las organizaciones, sus instituciones y sus ideologías para la toma de decisiones.

El concepto de tecnología puede ser asumido desde una polisemia de significaciones. Lo que interesa en la presente propuesta es recuperar, para la Tecnología, los espacios que permiten comprenderla en un sentido amplio que excede la materialidad, es decir, la Tecnología producto. En este sentido la Tecnología advierte también sobre los procesos tecnológicos en torno a los recursos, tanto materiales como humanos; la perspectiva ambiental, en relación con la capacidad de soporte del planeta; los perfiles productivos, considerando los atributos culturales del sitio, el conocimiento dispuesto, tanto sea académico como experiencial; la economía que dinamiza, en función de monopolios comerciales o no; el desarrollo que promueve, en términos de modelos incluyentes o excluyentes, y la política intrínseca de toda esta red de selección de atributos que manifiesta una definida ideología en torno a valores y ética.

La gestión tecnológica se comprende como la articulación de actores y sectores en torno a un entramado de decisiones en el cual los poderes sectoriales se ponen en juego y dirimen de manera democrática o no la promoción, instalación y ejecución de un tipo de tecnología 
u otra, y consolidan una matriz productiva de dependencia o de emancipación. De esta manera, la Tecnología queda expuesta en la totalidad de su significación pudiéndose reconocer en ella un complejo sistema de relaciones que es indispensable considerar en el momento de seleccionar una u otra, conscientes de la afiliación que eso representa.

\section{Sección teórica \\ La tecnología en su inmediatez}

\section{La dimensión democrática de la tecnología}

Frente al escenario reductivo de la productividad tecnológica humana $-\mathrm{y}$ se dice reductivo porque parece que hoy el hecho tecnológico carece de la subjetividad, la pasión y el arte de otras producciones humanas-, nos preguntamos si podemos entender la tecnología como el saber y el hacer de las personas comunes que, apelando al sentido común, producen y reproducen sus vidas cotidianas. Si la respuesta fuera: sí, eso es tecnología, ¿haría falta democratizar la tecnología si este supuesto infiere que su naturaleza es de por sí democrática? Punto. Bajemos el telón y a conversar de otra cosa. Ahora bien, si la respuesta fuera: no, eso no es tecnología, los convidamos a pensar en quiénes son los sujetos que saben hacer tecnología y por qué motivo habrían de querer democratizarla. Esto último para no parecer muy ingenuos. Aunque parezca redundante, desde este lugar es de donde creemos que podemos comenzar el relato de este artículo. Relato que se relaciona entonces con el saber-conocimiento-tecnológico, quiénes lo producen, cómo lo producen y para qué lo producen.

Queremos señalar que estamos haciendo una hipérbole entre "tecnología" y "saber-conocimiento". Intentamos generar una expresión cargada de sentido que fortalezca una dirección, de manera tal que ustedes, lectores, se encuentren dentro de casi una expresión lírica. Cuestión esta central para la tecnología, no tanto como un concepto, sino principalmente como experiencia afectiva, y por ello muy sensible. De lo dicho hasta aquí se desprende que la tecnología es un saber-conocimiento dinámico, colectivo y amoroso.

Pura acción. Pura performatividad. Permítannos una serie de reflexiones articuladas que argumentan esta posición. 
El saber-conocimiento es inherente al ser humano y siempre lo ha acompañado en su trayectoria. Es a partir de este saber-conocimiento que las personas se han asentado en su territorio, transformándolo (Queraltó, 1993). Pero, en este apartado, no deseamos focalizar específicamente en esta convencional consideración. Queremos referirnos, en tal caso, al saber-conocimiento como poder. El poder en su dimensión de hacer, transformar, tomar, cambiar, decidir y ganar. Entonces, el saber-conocimiento como ganar. El ganar en su dimensión de tener, poseer, producir, consumir y acumular. Finalmente, entonces: el saberconocimiento como acumular. Por transición, si el saber-conocimiento es tecnología, entonces la tecnología parece ser la sumatoria de poder, ganar y acumular.

Regreso a las conjeturas del inicio. Si la tecnología no es el saber-conocimiento de sentido común que se anida siempre, o casi siempre, en las acciones cotidianas de la gente, entonces la tecnología es lo que acabamos de expresar, es el saber ganar para acumular poder (WINNER, 1987). Y si fuera así, ¿quién va a democratizar ese jugoso bocado?

Desde dos perspectivas decimos esto. Una es aquella que relaciona la tecnología con el poder y el supuesto, un tanto ingenuo, que implica democratizarla. Otra es la que relaciona la tecnología con quien se supone la sabe y la hace, y el supuesto aleatorio que implica la legitimación de ese saber hacer, que nunca se extiende más allá de las universidades, los centros de investigación y otras parafernalias de la academia.

A lo largo de la historia, el saber-conocimiento ha estado monopolizado por grupos humanos que heredaron -o saquearon - la construcción histórica de ese saber. Si solo nos volvemos cinco siglos atrás, para no leer desde tan lejos a la modernidad, podemos recordar que en aquel tiempo era la iglesia la mediadora en el mundo de los conocimientos jerarquizados. Una iglesia asentada en la Europa occidental que reinaba con dominio sobre vastos territorios. Luego las colonias, la evangelización, el oro, la plata, el comercio y los epistemicidios. Muertes cognitivas de seres alados (Latour, 2013), hechiceras - mujeres, claro- negros, indios y bárbaros (Grosfoguel, 2013).

Poder, ganar y acumular. Y siguió la historia. Llega la ciencia. Un nuevo relato. La ciencia y su modernidad, de la mano del saber acumulado en las universidades y producido por castas intelectuales de promoción clasista. Un nuevo amo se instala en el mundo. Y construye su verdad: la verdad única, objetiva y universal. Aunque luego un poco revisada (LYOTARD, 1987). 
Otra vez reflexionamos ante tantos axiomas. Si el saber y el hacer de la gente común, en medio de sus vidas cotidianas, no es tecnología, pues entonces tecnología es, y solo es, lo que dice esa casta de intelectuales hacedores de saberes-conocimientos, que se instalaron como salvadores del mundo. Queremos interpelar a esta tecnología de elite, y para ello nos preguntamos ¿con qué nuevo poder se consigue desmantelar al poder hegemónico de ese tipo de tecnología? Democratizar la tecnología, en todo caso, sería callar, escuchar, mirar, aprender y dejar de silenciar, oscurecer ese saber-conocimiento "otro", construido en el fragor de la vida misma de todas esas personas que andan pensando cómo hoy, y cada día, resolverán sus problemas y alcanzarán sus expectativas y deseos.

Ahora sabemos que la provocación del inicio no es compañera de la Razón. La provocación, el desafío colocado en esta presentación, está puesto en la Pasión. La tecnología es experiencia y es pasión.

\section{La dimensión colaborativa de la tecnología}

El saber es un intangible producido en escenarios predispuestos a dicha producción. Las reglas, normas y leyes no siempre serán las que promuevan tales escenarios. Muchas veces, dice FEYERABEND (2010), estas disuelven las posibilidades del encuentro con los saberes diversos. Adherimos profundamente a esta visión. Desde este enfoque intentaremos reconstruir el concepto de construcción de un saber-conocimiento colectivo y emancipador.

El planteo que estamos trayendo aquí, para compartir con ustedes, está sostenido por dos construcciones de sentido: una de perspectiva teórica, alimentada por una corriente de pensamiento que revela la subalternización que produce la colonialidad, en la que intentamos bucear para sostener argumentos, y otra de perspectiva empírica, producto de nuestras experiencias de vida, a partir de la construcción colectiva de saberes-conocimientos-tecnológicos en varios sitios de nuestro país.

En relación con la primera construcción de sentido, nuestra postura se vincula con reflexiones que se entrelazan con nuevos relatos que narran una historia diferente, que de-construye la explicación moderna convencional, eurocéntrica y occidental de las ideas y procura poner en evidencia esta versión de discurso hegemónico que se expresa en un modelo 
civilizatorio que produce una ruptura ontológica entre cuerpo y mente, entre la razón y el mundo. Por este motivo, creemos, se produce una escisión entre la gente común y los especialistas, que profundiza, por transición, la distancia entre la cultura de ese público general y esos expertos. Cultura que se hace tecnología.

Este metarrelato moderno ha funcionado como un dispositivo de colonialidad que articula todos los pueblos, el tiempo y el espacio y derrumba otras formas de ser, de organizarse y de saber (Mignolo, 2010). Tanto la evangelización, la iglesia, como la civilización, la ciencia, tienen como sustento la idea de que hay un patrón civilizatorio superior a partir del cual las sociedades occidentales, modernas, constituyen la imagen deseada para el resto del mundo; es decir, parafraseando a LATOUR (2013), existe una sociedad que posee la verdad y otras que no la tienen y la emulan. Bajo esta significación, no es extraño pensar - y de verdad la mayoría de la gente lo piensa así, pues así hemos sido formados- que tecnología entonces no es el saber-conocimiento que tiene la gente común y que utiliza a diario para la resolución de sus vicisitudes, sino que es aquella desarrollada por un grupo experto y superior que conoce la verdad.

La revalorización y re-significación del actor latouriano, la gente común, es la que sostenemos en esta presentación, la idea de democratización y equilibrio de roles en la construcción colectiva de conocimientos. LATour (2008) confía en su actor social, y por ello sostiene que el viaje hacia esa nueva epopeya — no epopeya como el gran relato moderno sino como logro esclarecedor de un relato pequeño y particularizado- debe ser desprovisto de categorías premeditadas, producto de la intelectualidad, y debe llevar una velocidad muy lenta, para lo cual habrá que descender de los modernos transportes, instrumentos del análisis sociológico convencionales poco adecuados para el nuevo viaje, que no dejan ver la subjetividad y cognición propias de los actores reconstituidos como los conocedores (LATOUR, 2008), otra vez la gente común.

Ahora bien, volviendo a la construcción de sentido, basada en la perspectiva de la que les hablamos, se plantea lo siguiente: el saber-conocimiento es colectivo, por lo que el saber común participa, al igual que el saber experto, de los modos de conocer y hacer el mundo; esto da lugar al reconocimiento legítimo del “otro" en su forma de ser en el mundo, de-construyendo la forma hegemónica imperante. Por otro lado, se sostiene la idea de que el saberconocimiento no es para siempre, no es igual para todos y que se compone de una diversidad de saberes, que es lo que lo hace enriquecedor y colectivo; por lo tanto, co-construido. 
Esto quiere decir que los grupos locales, lejos de ser receptores pasivos y vacíos de las condiciones y calidades tecnológicas construidas por expertos y especialistas globales, configuran activamente los procesos a partir de los cuales se construyen tecnologías basadas en identidades propias de las prácticas culturales nacidas en la vida y hacer cotidianos de los territorios. Esta defensa del saber-conocimiento cotidiano, que presentamos hasta aquí, es política y epistemológica, y surge de nuestro compromiso con un discurso antiesencialista respecto de lo diferente, lo "otro", lo subalternizado. Es decir, el énfasis lo estamos colocando en la construcción colectiva de la tecnología; por lo tanto, es nuestra intención reconocer el saber-conocimiento de la gente común como poder, para imaginar puentes con aquel saber experto, en un sentido esperanzador de resistencia frente a lo impuesto. Si así fuera - y no decimos que lo sea— no se debería estar pensando ahora en democratizar la tecnología.

En relación con la segunda construcción de sentido, intentaremos presentarla desde un estilo literario que parezca un cuento (Peyloubet, 2018) en la próxima sección.

\section{Sección empírica}

\section{La experiencia tecnológica cognoscente}

\section{Experiencia de desarrollo tecnológico democrático y colaborativo}

Así sucedió una vez en Concordia. No es un cuento. Fue real.

Corría el año 2010 en Argentina. Las inundaciones ya no eran el problema de la región del litoral. Aunque había habido otras muchas, ninguna de la envergadura de la del 98 . El litoral se alzaba como el gran gigante forestal de nuestro país. Los productores regionales habían comprendido claramente que la madera era un recurso que debía considerarse, y que tal como otros recursos debía promoverse. La decisión de producir árboles debatía con la idea de usar el árbol. La composición ideológica de preservar el bosque nativo, regalado por la madre tierra, era un bien insoslayable. La madera como material era un bien de producción humana y debía comprender lo que esta producción impactaba. Desde esta perspectiva, la seductora idea de usar lo que la naturaleza provee quedó convertida en el concepto de abuso, y el llamado fue a considerar qué tipo de producción es posible en el 
marco del menor impacto. Las producciones humanas siempre impactan en el territorio. No es posible pensarlas en otros términos, salvo que comencemos a pensar en, por lo menos, disminuir los impactos. La experiencia en Concordia hizo promesas al respecto.

Llegamos a Concordia de la mano del intendente. Para aquel entonces ya no éramos unos jóvenes becarios. Habíamos madurado algunas cuestiones y éramos investigadores del CONICET. Habíamos pasado la puerta — que en aquel tiempo ya era estrecha y ni hablar de lo que es ahora-, y las posibilidades de que nos escucharan habían aumentado. Era otra oportunidad para repensar los modos de investigar que habían sido nuestro desvelo años atrás, pero ahora se sumaba la convicción de la utilidad social de la investigación de manera fuerte y visible. La utilidad de la investigación inserta en una región específica y en un contexto nacional de características errantes, procurando colaborar en una necesaria transformación.

El municipio, en el inicio de esta experiencia, fue sólido y se presentó como un buen guardián del bien común. La producción forestal se promovía como una actividad incipiente para la región, podía generar trabajo autónomo en una cadena productiva donde se intentaban instalar nichos de valor bajo un sistema de renta distribuida. El diseño de un sistema constructivo de madera otra vez se ponía en el frente y peleaba, desde larga data, las autonomías laborales y productivas como un asunto local de interés municipal. Municipalidad y productores en sus diversas fases aliados para un mejor desempeño de las capacidades productivas regionales. Productores forestales, aserraderos y carpinteros insertos en una lógica complementaria de producción. Pero no era feliz todo al momento. Las disputas entre las partes se hacían sentir. Las economías más poderosas procuraban digitar decisiones sin mediar con las pequeñas. La historia de siempre. El asunto en esta experiencia es que allí estaba el municipio para equilibrar estas disputas, y aunque no todo fue posible, dichas disputas terminaron por fortalecer, con el correr del tiempo, las economías pequeñas haciéndolas más visibles y ganando espacios de interlocución.

La tecnología gestión, impulsada por el municipio como actor de decisiones, fue derivando en un espacio más colectivo donde la información circulaba de manera más clara. En este intento por desactivar las hegemónicas maneras de hacer, gestión del poder, se avanzaron pocos casilleros, pero se avanzaron. Apareció en el tapete el acervo productivo y cultural de un grupo de carpinteros locales organizados como asociación, con quienes trabajamos 
de manera fraterna durante toda la experiencia y con quienes llevamos adelante el cambio de la historia, no dicho de manera grandilocuente, sino haciendo referencia a la historia pequeña de nuestras vidas, la de todos, y a la historia de la producción pequeña inserta en el círculo de las decisiones grandes. Todo esto sin soberbia y sin cambio de valores. Los carpinteros, los mismos del inicio a hoy, solo en una posición mucho más iluminada.

La tecnología producto nos encomendó al Eucalyptus Grandis. En un contexto productivo, derivado del mercado y los negocios, Concordia producía para el país tablas para pallets y encofrados. Destinos un tanto menores para una madera de tan alta belleza y prestigiosa mecánica.

Las producciones forestales en Argentina se asientan sobre especies exógenas implantadas, principalmente a partir de la década del 80, cuando se promulgó la Ley 25080 que promovía la forestación sobre tierras improductivas, llámese no ganado, no agricultura. La industria maderera en nuestro país tuvo un comienzo poco pensado, y aunque la ley mencionada aparece como una gran idea, lo cierto es que no hubo una planificación general y sustentable por parte del Estado en este sentido, y la producción se hizo al parecer del inversor. En este contexto se generaron algunas crisis, y lo que podría haber sido productivamente bueno y ambientalmente cuidado se convirtió en muchos casos en una depredación imperdonable.

No obstante, así, y en una Concordia inserta en una región principalmente forestal, comenzamos a transitar la producción hacia el lugar menos malo. Descubrimos que la producción forestal de la zona tenía en sus filas a múltiples productores, que en la mayoría de los casos se trataba de producciones familiares o de inversión a escala pequeña, que movían una economía más doméstica, y que en algunas ocasiones se mixturaban con ganado. Los aserraderos eran también muy diversos en tamaño y capacidad de producción y generaban un empleo nada despreciable. El problema recurrente en todos los casos era el aserrín de la madera que no encontraba un nicho productivo favorable y que en algunos casos se quemaba, lo que generaba multas por parte del municipio ante esta defraudación ambiental.

Aparece en escena una gran corporación de capitales mixtos que está en Argentina asentada bien precisamente en Concordia. Una fábrica de gran tamaño de placas y subproductos de la madera, con una inversión en maquinaria e infraestructura bien consolidada, en un mercado cuyos atributos promueve la vida de los grandes capitales empresariales, claro 
está. El aserrín pasa a ser residuo de aserraderos con valor monetario negativo, y para la gran empresa pasa a ser el principal insumo para la producción de sus placas, con envío a todos puntos del país y el exterior con magnífica ganancia. Gran negocio para algunos y tranquilidad en el sueño para otros. Mientras unos crecen aceleradamente sin ninguna discusión ética, otros solo pueden dormir mejor sin presiones ni multas.

Todas estas cosas fuimos aprendiendo al transitar el territorio y comenzar a compartir con la comunidad. La percepción desde el municipio al respecto no era esta. El municipio generaba alianzas con la gran empresa en vistas del empleo local que creaba, pero no podía advertir la construcción conceptual del abuso económico que se producía en la negociación de los residuos de la madera, como el aserrín.

Esta parte del relato tiene la lucha en el campo de las ideas, que parece que nunca llegan a la realidad, tocando la tierra y a su gente, y se pierde en enormes discusiones de congresos y seminarios de la elite universitaria. Teníamos frente a nuestra nariz la impronta del abuso del capital sobrevalorado en relación con el trabajo y los efectos de los sectores poderosos negociando con los que no lo son. Concordia trajo esa reflexión. Que no fue neutral, tiñó sin dudas las siguientes decisiones de todo el grupo que intentaba pararse desde una tecnología más democrática y concertada.

Así mismo, se fue construyendo el argumento del porqué trabajar con la madera, a pesar de nuestra conciencia ambiental, en tanto la atraviesa la producción humana que no puede declinar sino tan solo volverse menos impactante, y eso sí fue parte de nuestras búsquedas. Ser menos impactantes ambientalmente, apalancar las economías vulnerables, promover formas de producción asociativas y cooperativas, alertar acerca de la distribución justa de la rentabilidad productiva en toda su cadena de valor, co-diseñar un producto de propiedad colectiva abriendo cajas negras y desjeraquizar los saberes académicos frente a los saberes técnicos y otros, con la convicción profunda de que una vida basada en estas prerrogativas solo podría co-construir un hábitat mejor.

La co-construcción se fue consolidando en esta nueva experiencia concordiense. Los carpinteros se convirtieron en nuestros principales socios de la aventura, junto al municipio, que desde una primera instancia se posicionó acompañando este proceso con impronta de bien común. 
Múltiples encuentros tecnológicos en el taller. Matrices armadas y desarmadas. Componentes prefabricados en un sistema estandarizado. Simulaciones montadas y desmontadas. Nuevos instrumentos de precisión inventados por el saber consolidado de cada participante, nosotros y ellos, aprovechando el anclaje cognitivo de la experiencia concebida colectivamente. La tecnología producto trajo consigo una Certificación de Aptitud Técnica. La propiedad de esta certificación quedó en esta ocasión a nombre de la Asociación de Carpinteros junto al Municipio. Gestión asociada, público-privada, para obtener la propiedad de un bien que, convertido en servicio, podía generar ganancia. Ganancia que al Municipio le podría dejar planes habitacionales para su comunidad subsidiados por el Estado Nacional y generación de empleo a través de la obra pública, así mismo la tracción de un recurso productivo local, como es la madera, que también desencadenaba empleo e ingresos locales. Ganancia que a la asociación de carpinteros le podía dejar la producción de componentes prefabricados y la construcción de vivienda puesta en el mercado privado como en la demanda pública de los planes habitacionales mencionados. Pero esencialmente una ganancia que no quedaría limitada al capital monetario, sino —y más fuertemente entendido— al capital social y cognitivo de aquellos carpinteros que, superando toda visión convencional del saber técnico estigmatizado como "de segunda", fueron parte de una nueva historia que, con valor y mucho esfuerzo, se fue escribiendo en Concordia y relató el nacimiento de procesos productivos con sabor a iguales y cantó con voces claras la inesperada odisea de un devenir expectante opositor a la injusticia. La tecnología ya en este caso se mutó en política, y cambió la vida de todos los que pudimos seguirla. Caminamos conscientes por un camino valiente.

Los carpinteros de la asociación siguieron escribiendo la historia, y junto a nosotros, para este entonces ya amigos inseparables, empezamos a recorrer senderos no planificados que fueron presentándose en el artilugio de los vínculos. Otro capital de los carpinteros. Nada quietos, nada callados, esgrimiendo orgullosos toda su experiencia. Producción y construcción de un salón de usos múltiples para un barrio de Concordia, de viviendas de madera para familias vulnerables, de estaciones saludables urbanas, de un galpón de reciclado de residuos urbanos para la ciudad de Concordia y otros posibles en la región, talleres de capacitación en el marco de programas de formación de oficio en diversos municipios de la provincia, gestores colectivos de proyectos de investigación de Ciencia y Tecnología y hasta vinculadores de ideas tecnológicas. El desafío de esta experiencia fue en realidad aprender a reconocer que los atributos materiales de la tecnología producto derramaron sobre la tecnología gestión y proceso los mejores resultados. Ya ninguno es el mismo. 


\section{Sección metodológica \\ Coherencia argumental propositiva}

\section{La conversación como puente entre saberes}

Mediante estas dos construcciones de sentido presentadas en la primera sección teórica, refrendada en la experiencia tecnológica de la sección empírica, intentamos revisar la condición cognitiva en la articulación del saber tecnológico de sentido común, legitimado por la práctica cotidiana, y del saber tecnológico de la academia, legitimado por la modernidad, y a partir de ello recuperar el valor superlativo de la integración de saberes-conocimientos que se entrelazan en territorios comunes, donde las necesidades dan curso a la realidad sentida y se materializan en puentes de comunicaciones mutuas.

En el caso compartido, pretendimos manifestar una experiencia en la cual surgen situaciones que revelan coexistencias de conocimientos diferenciados que se pueden poner en estado de igualdad y componer en una nueva versión cognitiva revalidada. Todo un esfuerzo metodológico que intentó construir nuevas herramientas con las cuales reconocer al "otro" en su verdadera dimensión.

Aceptar que los sujetos cognoscentes somos todos aquellos que participamos de la experiencia del producir conocimiento generando una construcción colectiva es una característica singular de la posición que intentamos construir hasta aquí. Así también fortalecemos la deconstrucción de rol experto del académico como el único productor de saber.

La propiedad privada, en tanto productora de quiebres e intereses individuales, se procura recualificar a través del cruce de conocimientos colectivos, que pone en vigencia la autoría mixta y la co-construcción de conocimiento, y desarma las típicas cajas negras que dan lugar a elites propietarias de saberes que se empoderan a sí mismas.

Participar de procesos en los que se co-construyen saberes-conocimientos (tecnológicos en este caso, pero podrían ser otros no necesariamente instrumentales) implica generar un diálogo, una conversación. La conversación parece ser el modo, la forma en que participan los que concurren a este proceso. Comprender que este proceso colectivo de construcción de conocimiento es una conversación implica hacer lugar a un relato consensuado, en el cual 
no solo se habla, sino que se escucha. Los procesos de desarrollo de tecnología pueden ser $-\mathrm{y}$ no es que necesariamente hoy lo sean- escenarios de pluralidad igualitaria donde se materializan, en el sentido de la instrumentalización misma, las respuestas y las formas de acomodarse en el planeta, donde conviven los anhelos, expectativas y deseos de las diversas personas que confabulan la relación sociedad-naturaleza.

La modernidad nos ha convencido de que esta convivencia no debe ser tal, que las conversaciones las lideran quienes saben, los expertos, y eso ha dado lugar a una construcción de conocimientos tecnológicos que obvió los saberes enraizados en los valores culturales, particulares y subjetivos y fortaleció el saber global instaurado por la universalidad y la objetividad.

La posición ideológica de esta presentación apasionada se asienta sobre la valoración del potencial creativo e intelectual de la comunidad en su conjunto. Es necesario recomponer los roles en la construcción de un colectivo social. La noción de jerarquía social, en tanto denota poder encubierto, debe ser destituida por la noción del rol social, en que cada miembro del grupo se posiciona libremente de acuerdo con sus competencias, entendidas como virtudes, saberes, expectativas y desafíos. Esta nueva construcción de lo social descompagina antiguas estructuras, y por ello podrían aparecer otras formas de manifestar las nuevas expresiones del conocimiento de un colectivo social revalorizado (РеyLoubet, 2014).

Las conversaciones de las que hablamos en esta presentación tratan de profundos encuentros en los cuales quienes participan crean un espacio de reconocimiento y valoración secundada por la reivindicación de cosmovisiones pasibles de ser confraternas. Aceptar que este desarrollo de conocimientos tecnológicos es análogo a una conversación de pares, amigos, supone un avance extraordinario. Es romper con los hábitos de las transferencias tecnológicas en las que se inmolan los saberes silenciados y dan lugar a un saber experto legitimado y convalidado por una hegemonía autoritaria y necia. Las capacitaciones, engendradas por la caridad intelectual, explotan, se derrumban, frente a un diálogo de amigos que comparten saberes. Las capacitaciones son el instrumento de la transferencia. Las capacitaciones son lobos vestidos de ovejas. Y las transferencias son nuevos instrumentos de colonialidad de la modernidad. Las conversaciones de las que hablamos y a las que aspiramos, con sublime convicción, subvierten esta incapacidad de valorar al otro e instalan un nuevo concepto: co-construcción del conocimiento. Entonces conversemos. 
Ahora bien, las conversaciones tienen contenidos y formas. En una percepción semántica, conversar es expresar a viva voz el pensamiento interno. Conversar puede igualmente generar la violencia de la jerarquía en el uso de la voz y del silencio. Por eso no basta creer que la construcción de conocimiento es a través de una conversación. Hay que hacer de esta una entrega. Disolver las jerarquías en las conversaciones entiende que conversar es hablar y principalmente escuchar. Escuchar la voz, modo coloquial extensamente utilizado, y escuchar el silencio, gesto situado de calada profunda. De más está decir que nosotros creemos que el silencio es parte de la conversación. Al valorar el silencio como tal, quien lo decide está participando. Si el silencio fuera la no participación, expresaría que quienes callan no existen, no participan de la conversación propuesta. Esto no es así. Los modos de participación, en las conversaciones que construyen conocimientos plurales no jerárquicos, son absolutamente diversos y libres. La voz de algunos y el silencio de otros comparten el sentido de horadar las desigualdades para crear juntos el saber colectivo (YеніA, 2007).

En términos filosóficos, la posición que esgrimimos en esta presentación intenta de-construir la hegemonía epistémica y desenmascarar los mecanismos con que la modernidad, hegemonía científica como único saber, legitima cierto saber e invisibiliza lo que conoce como conocimientos subalternos produciendo no existencias. Cambiar las condiciones de conversación hacia un modo igualitario de conversar quiere decir reconocer el saber que se produce de otro modo. Eso hará que la conversación cambie en sus contenidos, cuando aceptemos otras formas tanto de hablar como de no hablar. No es suficiente entonces querer cambiar los contenidos de la conversación de forma repentina, eso sería una lucha no entendida; hay que cambiar los modos en que se conversa, de esa manera los contenidos “otros” aparecerán naturalizados. Esto perpetuaría un nuevo paradigma, no hegemónico sino plural. Esta propuesta aquí se hace clave, ya que nos estamos rehusando a codificar y/o recodificar nuevos contenidos; nos preocupan esencialmente los modos. Solo así es posible que aparezcan otras condiciones de existencia y se develen los nuevos contenidos no previamente marcados.

El componente generador de este cambio en la comprensión de lo social es, sin duda, la recuperación del rol cognoscente, hacedor de conocimiento porque sabe, de la comunidad que genera asociaciones. Si bien esta es una especulación de rango epistémico para el abordaje y construcción del nuevo saber-conocimiento, es en sí misma un cambio en el cual los hacedores del saber son todos desde su potencial, tanto cognitivo como creativo, lo que 
restablece el valor para todo aquello que se construye desde los sentidos, sean estos los más diversos. Aceptar esta condición colectiva de constructores de saber impone reconocer todas las tradiciones.

\section{Conclusiones no finales

Construcción interactoral del conocimiento

\section{Seres alados y de ficción}

La mayoría de las tensiones que aparecen en una construcción dialógica colectiva suceden por conversar de un modo frente a las condiciones de conversar de otro modo. Para sofocar estas tensiones se supone que se acepte el pluralismo de los modos y por tanto la pluralidad de las claves con que se conversa y la pluralidad de las claves con que se escucha. Esa aceptación impone hacer perder poder a la palabra para recuperar posiblemente otras entidades que no se dan a través de la palabra (Latour, 2013), otros gestos y expresiones que capitalizan igualmente un saber otro.

LATOuR nos convida a pensar en la sociedad como productora de conocimientos asociados, al señalar la existencia de una sociología de asociaciones (Latour, 2008). Entendemos, junto a él que el conocimiento vuela en un cielo de asociaciones entre personas que hay que seguir, rastrear. Al dirigir la atención a esas prácticas y encuentros de saberes articulados, lo que se tiene por delante son múltiples realidades. Ontologías.

La existencia de esa multiplicidad ontológica supone no una sola forma de entender y hacer, sino una pluralidad en los modos de entender y, por lo tanto, será necesario integrar esos modos de conversación en una coexistencia de saberes múltiples. Ayuda entonces a esta coexistencia la desactivación del lenguaje coloquial para dar lugar a otras formas de expresión significantes en esos modos múltiples.

Se crean así los seres de ficción (Latour, 2013), que están lejos de comprenderse como seres opuestos a la realidad, ya que no son mentira ni falsos, ni imaginarios, sino que son los personajes susceptibles de experimentar la aventura de integrarse con el "otro". Gesto necesario para la construcción de saberes-conocimientos pluriversales. 
Esos seres angelados (Latour, 2013) son los portadores de la conversión; que la razón no consiga seguirlos no significa que no existan. Condición indispensable, otra vez decimos, para la construcción colectiva de un saber performativo. ¿Co-performatividad será una redundancia para el saber-conocimiento-tecnológico que se construye en una conversación como de la que aquí hablamos? No, supone ontologías múltiples, no ontología en singular sino en plural, para señalar enfáticamente esa pluralidad, multiplicidad de voces, lenguajes y gestos que dan cuenta de la conversabilidad entre diferentes jerárquicamente igualados y creativamente vinculados.

Los saberes-conocimientos y sus procesos de producción obedecen a diferentes tradiciones cognitivas. Nosotros creemos que la tecnología hegemónica actual posee un estilo cognitivo, y por tanto se convierten en una tradición más de las muchas que existen. Por eso pensamos que es posible recuperar otras formas de producir saberes-conocimientos-tecnológicos. A lo largo del tiempo, la humanidad ha dado a luz un sinnúmero de tradiciones tecnológicas que sellaron los siglos con caracterizaciones, debates y controversias en cuanto a su legitimación, siempre asociada al poder.

Lo que es claro es que algunas formas de conocer y algunos saberes fueron desplazados y otros tuvieron la habilidad para penetrar en la sociedad, dando cuenta con ello de una construcción política. El saber-conocimiento se erige verdadero a partir de mecanismos de legitimación ideológicos, que denotan en esta producción humana una existencia de poder por un lado y subordinación por otro en torno a las ideas y el pensamiento.

La nueva base cognitiva cooperativa, que estamos proponiendo teóricamente, presentada como una forma de conversación en la cual se co-construye el saber-conocimiento, como así también la experiencia tecnológica del relato de Concordia revelan criterios de legitimación según tradiciones cognitivas alternativas que desean no ser subalternizadas y generan una transición, puentes, entre el conocimiento experto hegemónico y el saber-conocimiento de sentido común emanado de tradiciones no hegemónicas.

Finalmente, nos gustaría compartir las siguientes reflexiones: $i$ ) el saber-conocimiento de sentido común es productor de la resolución, a diario, de los múltiples problemas que los sujetos enfrentamos en nuestra vida cotidiana; ii) el proceso cognitivo que construye el sentido común, considerado un tipo de saber, es posible de ser legitimado con derecho en 
una versión propia de proceso cognitivo alternativo; iii) los procesos que engendran construcciones colectivas-democráticas se dan a partir del reconocimiento y valorización de un saber plural; iv) los diversos estilos cognitivos, enmarcados en tradiciones científicas o no, deben ser considerados como potenciales de resolución de problemas; $v$ ) los saberes ausentes, omitidos, deben recuperarse como potenciales de emancipación colectiva; vi) la legitimidad de un cuerpo de saber no depende solamente de su contenido de verdad, sino de las fuerzas institucionales y las matrices disciplinarias que regulan la producción y autorización del saber.

Para finalizar, queremos expresar que, en algún sentido, esta presentación intenta poner a la luz una injusticia cognitiva que parte de una jerarquización de saberes, que siendo diferentes son promovidos como desiguales. No habrá justicia social sin justicia cognitiva, dice aproximadamente SANTOS (2009).

Soslayar la forma de producir conocimiento hegemónico, para dar lugar a otras formas de producir otros conocimientos que sean portavoces de contextos socio-históricos y culturales diversos y muchas veces omitidos provoca en el medio académico una alerta, ya que se juegan instancias de poder en torno a dicho saber. Si el saber no está sostenido solamente por las seguras versiones de castas intelectuales de claridad, objetividad y verdad; si se reconoce que el saber también se encuentra en las personas que producen historia y cultura cotidiana; el saber es entonces una producción colectiva y no solo de expertos. Esto desplaza el poder de un sabio individual a un sabio colectivo (Feyerabend, 2010), principio epistémico que sigue esta presentación que estamos haciendo aquí.

La plataforma cognitiva que hemos intentado compartir hasta el momento considera una múltiple confluencia de saberes que, de manera cooperativa, sin reservas ni cajas negras, procura complementarse y dar lugar a una co-construcción de saberes y conocimientos de propiedad colectiva, que beneficia, en igualdad de condiciones, a la comunidad en general y la hace, en todo caso, experta en su totalidad.

Manifestamos ahora: rango de epistemia para el saber-conocimiento de sentido común, retomando la provocación, el desafío del inicio, cuestionando la jerarquización de los conocimientos, para dar lugar a una nueva convención que recupere el saber-conocimiento (tecnología) de los expertos de la vida cotidiana. Llegamos así a la pregunta final: ¿quién tiene 
la capacidad, el poder o la autoridad, en todo caso, para democratizar la tecnología? La tecnología no debe democratizarse, pensamos hacia el final, debe nacer democrática, debe ser instrumento de igualdad cognitiva. Que lo pensemos entre todos, para que se haga posible.

\section{Bibliografía}

DAGNINO, Renato (2010) Tecnología Social: ferramenta para construir outra sociedade. Ed. KACO, Campinas.

FEYERABEND, Paul (2010) Tratado contra el método. Siglo XXI (Orig. 1975), México DF. GROSFOGUEL, Ramón (2013) Para una descolonización epistemológica del paradigma moderno de conocimiento. CEIICH-UNAM. Programa de investigación: El mundo en el Siglo XXI. Recuperado de www.youtube.com/watch?v=DYks4qCoZEo.

LATOUR, Bruno (2008) Reensamblar lo social. Una introducción a la teoría del actor red. Manatial, Buenos Aires.

LATOUR, Bruno (2013) Investigación sobre los modos de existencia. Una antropología de los modernos. Paidós, Buenos Aires.

LYOTARD, Jean Francoise (1987) La condición postmoderna. Informe sobre el saber. Cátedra, Madrid.

MIGNOLO, Walter (2010) Desobediencia epistémica: retórica de la modernidad, lógica de la colonialidad, gramática de la descolonialidad. $1 .^{\text {ra }}$ Ed. Del Signo, Buenos Aires.

PEYLOUBET, Paula (2014). "Rango epistémico al saber de sentido común”. Revista de Antropología Experimental. Universidad de Jaén, 14, 53-65, España.

PEYLOUBET, Paula (2018) Convidar Tecnología. Una propuesta a partir de la co-construcción. Diseño Ed., Buenos Aires.

QUERALTó, Ramón (1993) Mundo, Tecnología y Razón en el fin de la modernidad. ¿Hacia el hombre more técnico? Ed. PPU, SA. Barcelona.

SANTOS, Boaventura de Sousa (2009) Una epistemología del sur: la reivindicación del conocimiento y la emancipación social. Siglo XXI Ed., México DF.

WINNER, Langdon (1987) La ballena y el reactor. Una búsqueda de los límites en la era de la alta tecnología. Ed. Gedisa, Barcelona.

YEHIA, Elena (2007). "Descolonización del conocimiento y la práctica: un encuentro dialógico entre el programa de investigación sobre modernidad/colonialidad/decolonialidad latinoamericanas y la teoría del actor-red”. Tabula Rasa, 6, 85-114. Colombia. 